\title{
Virus papiloma humano, infecciones de transmisión sexual y microbioma vagino cervical en el desarrollo de lesiones premalignas y malignas del cuello uterino.
}

\author{
Marta Ramos ${ }^{1}$, Mónica Moreno ${ }^{2}$, Diana Callejas ${ }^{3,4}$ y Luis Télles 5 \\ ${ }^{1}$ Universidad Técnica de Ambato. Ambato, Ecuador. \\ ${ }^{2}$ Hospital Andino Riobamba, Riobamba, Ecuador. \\ ${ }^{3}$ División de Postǵrado Facultad de Medicina, Universidad del Zulia. Maracaibo, \\ Venezuela. \\ ${ }^{4}$ Facultad Ciencias de la Salud. Universidad Téenica de Manabí, Portoviejo, Ecuador. \\ ${ }^{5}$ Departamento de Microbiología. Universidad de Los Andes. Mérida, Venezuela. \\ Palabras clave: virus del papiloma humano; infeceiones de transmisión sexual; \\ microbioma vagíno cervical; cáncer de cuello uterino.
}

Resumen: Estudios recientes han descrito que la alteración de la microbiota vaginal y cervical podría conllevar a un microambiente propicio para el desarrollo de lesiones neoplásicas cervicales bajo ciertas infecciones. Los cambios en las comunidades bacterianas, elevación del $\mathrm{pH}$, la vaginosis bacteriana y las infecciones de transmisión sexual (ITS) pueden alterar el microambiente cervicovaginal y permitir la persistencia de microorganismos como el virus papiloma humano (VPH), promoviendo el desarrollo de displasia cervical. El presente estudio identificó evidencias bibliográficas de asociación entre la infección con VPH, otras ITS, y el microbioma vagínocervical en el desarrollo de estas lesiones. Se consultaron fuentes originales de las bases: PubMed, Sciencedirect, Springerlink, sin limitación en fechas de publicación; se utilizaron los siguientes descriptores: «Infecciones de transmisión sexual y cáncer cervical», «microbiota vaginal, infección por VPH y neoplasia cervical intraepitelial», «microbiota vaginal y cervical» $\mathrm{y}$ «relación entre cáncer y microbiota vaǵinal». La muestra final fue de 43 publicaciones. El VPH oncogénico se ha asociado significativamente con $G$. vaginalis $(\mathrm{p}<0,025)$, la cual se ha detectado hasta un $91,9 \%$ en mujeres con lesiones cervicales, mostrando mayor detección en lesiones intraepiteliales de alto grado (LIEAG). La depleción de Lactobacillus y una mayor diversidad microbiana facilitan la infección por el VPH y podrían estar involucrados en la persistencia viral y el desarrollo del cáncer. Es importante la detección de estas asociaciones microbianas, que actúan como cofactores en el desarrollo de lesiones cancerosas, facilitando la persistencia de la infección por VPH oncogénicos y, por ende, el desarrollo de cáncer.

Autor de correspondencia: Luis Téllez. Departamento de Microbiologia, Universidad de Los Andes, Mérida, Venezuela. Correo electrónico: letellezsenator@gmail.com). 


\title{
Human papillomavirus, sexually transmitted infections and cervicovaginal microbiome in the development of premalignant and malignant uterine cervix lesions.
}

\author{
Invest Clin 2019; 60 (4): 336-351
}

Key words: human papilloma virus; sexually transmitted infections; vagino cervical microbiome; cervical cancer.

\begin{abstract}
Recently studies have described that the alteration of the vaginal and cervical microbiota could lead to a favorable microenvironment for the development of neoplastic cervical lesions under certain infections. Changes in bacterial communities, $\mathrm{pH}$ elevation, bacterial vaǵinosis and sexually transmitted infections (STIs) can alter the cervicovaginal microenvironment and allow the persistence of microorganisms such as the human papilloma virus (HPV), promoting the development of eervical dysplasia. The present study identified bibliographic evidences of associations between infection with HPV, other STIs, and the vaginocervical microbiome in the development of these lesions. Original sources of the bases were consulted: PubMed, Sciencedirect, Springerlink, without limitation on dates of publication; were used: «Sexually transmitted infections and cervical cancer», «vaginal microbiota, HPV infection and cervical intraepithelial neoplasia», «vaginal and cervical microbiota», «Relationship between cancer and vaginal microbiota». The final sample was 43 publications. Oncogenic HPV has been significantly associated with G. vaginalis $(\mathrm{p}<0.025)$, and it has been detected up to $91.9 \%$ in women with cervical lesions; showing greater detection in high-grade intraepithelial lesions (LIEAG). Depletion of Lactobacillus and greater microbial diversity facilitate HPV infection and may be involved in viral persistence and eancer development. It is important to detect these microbial associations, which act as cofactors in the development of cancerous lesions, facilitating the persistence of oncogenic HPV infection, and therefore the development of cancer.
\end{abstract}

Recibido: 03-02-2019 Aceptado: 16-10-2019

\section{INTRODUCCIÓN}

Infecciones de Transmisión Sexual (ITS) como Problema de Salud Pública asociado a Cáncer

ITS como la sífilis, gonorrea, clamidiasis y tricomoniasis se describen como curables. Otras, como la hepatitis $\mathrm{B}$, herpes simplex (VHS), VIH/SIDA y papilomatosis humana, son infecciones virales persistentes, aunque existen tratamientos capaces de atenuar o modificar los síntomas o la enfermedad (1).
De acuerdo a la Organización Mundial de la Salud (OMS) estas infecciones afectan la salud sexual y reproductiva en el mundo, figurando como una de las cinco principales razones de atención médica en adultos (2).

Diariamente más de 1 millón de personas contraen una ITS. Se estima que anualmente unos 357 millones de personas contraen alguna de las siguientes: Clamidiasis (131 millones), blenorragia (78 millones), sífilis (5,6 millones) y tricomoniasis (143 millones). El número de personas con in-

Vol. 60(4): 336 - 351, 2019 
fección genital por el VHS supera los 500 millones; hay más de 290 millones de mujeres infectadas con VPH, provocando alrededor de 528000 casos de cáncer cérvico uterino y 266000 defunciones. Los microorganismos más frecuentes son: Chlamydia trachomatis, Neisseria gonorrhoeae, Treponema pallidum y Trichomonas vaǵinalis. A larǵo plazo, las ITS sin tratamiento podrían aumentar el riesgo de cáncer (3).

Se describe que las ITS representan un co-factor importante para la progresión de lesiones cervicales asociadas a infección por VPH (4). El estilo de vida junto a infecciones por C. trachomatis, VHS y el VIH, y la presencia de vaginosis bacteriana, han sido identificados como posibles cofactores involucrados en la carcinogénesis cervical (5). Las mujeres que cursan con infección por VPH, también pueden resultar positivas para la infección por C. trachomatis, teniendo alto riesgo de desarrollar cáncer cervical (CC) $(5,6)$. Este agente bacteriano se ha relacionado significativamente con un mayor riesgo de $\mathrm{CC}$ en estudios prospectivos y retrospectivos, y se ha identificado como un factor predictivo independiente de cáncer cervical en 11 estudios.

Según el tipo histológico ha mostrado un riesgo elevado para carcinoma de células escamosas y adenocarcinoma (5). Un posible mecanismo para que la infección por $C$. trachomatis aumente el riesgo de cáncer es la respuesta inflamatoria asociada a la infección, lo que lleva a una producción reactiva de metabolitos oxidativos y radicales libres, aumento de la expresión de citoquinas, quimiocinas, factores de crecimiento y angiogénicos y disminución de la inmunidad mediada por células, todo lo cual puede causar inestabilidad genética. Los efectos genómicos se observan en la producción de centrosomas supernumerarios y defectos de segregación de cromosomas, facilita la mitosis multipolar, promueve activamente la inestabilidad de los cromosomas, causa multinucleación $\mathrm{y}$, por lo tanto, conduce a la transformación y el desarrollo del tumor $(7,8)$.
Por otro lado, interrumpe las uniones célula-célula dependientes de N-cadherina y genera la descomposición del complejo $\mathrm{N}$-cadherina/ $\beta$-catenina demostrado en cultivos primarios de células epiteliales cervicales humanas y en células HeLa. También, desequilibra la metaloproteinasa 9 de matriz, y la proteína rica en cisteína inductora de la reversión con motivos de Kazal (RECK) durante la inflamación cervical. En esta misma línea, se demostró que la infección en ratones con C. trachomatis produjo un aumento significativo de la proliferación celular dentro del cuello uterino, y su asociación a la displasia cervical (5).

Numerosos estudios sugieren que la ocurrencia dual de infeceiones por VPH y VIH pueden incrementar la incidencia de CG y del Síndrome de Inmunodeficiencia $\mathrm{Hu}$ mana (SIDA) en las pacientes que las sufran (9). Entre los cánceres asociados al VIH se describe el cáncer cervical; la propia replicación del VIH puede fomentar el desarrollo de cáncer, potencialmente a través de la inducción de señales anǵiogénicas, antiapoptóticas o proliferativas. Otros mecanismos que se están explorando incluyen la activación inmune, el agotamiento inmune y la integración del VIH (10).

Un metanálisis de 200 estudios y más de 1 millón de mujeres con un examen citológico cervical normal reportó detección del ADN de VPH en un $12 \%$ en todo el mundo, aunque con una variación geográfica notable. Las regiones de detección frecuente de VPH incluyen regiones de África Sub-Sahariana (24\%), América Latina y el Caribe $(16,1 \%)$, Europa del Este $(14,2 \%)$, y Asia sudoriental (14,0\%) (11).

Existen más de 200 tipos de VPH caracterizados hasta el 2018, los genotipos 16 y 18 se han relacionado a más del 70\% de los cánceres (12). El VIH aumenta el riesǵo de cáncer de cuello uterino al favorecer la persistencia del VPH, en contraste con el VPH en mujeres sin VIH cuyos sistemas inmunitarios a menudo eliminan la infección (10). El riesgo de CC en mujeres con VIH aumenta 
con la edad y no tiene asociación directa con

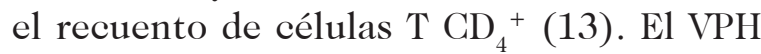
se asocia al cáncer de células escamosas del cuello uterino, pero también a cáncer de vulva, vaǵina, pene, ano y orofaringe (14).

La inflamación crónica debida a la coinfección con otros microorganismos se ha asociado fuertemente con la progresión de la lesión cervical (15). La inflamación cervical puede estar asociada con lesiones de alto grado (LIEAG) y puede ser un cofactor para lesiones de este tipo en mujeres infectadas con VPH oncogénico. En otros tipos de cáncer, independientemente del agente causal, la inflamación crónica expone al tejido a daños genotóxicos constantes.

En el cáncer de cuello uterino, la inflamación crónica sumada a los cambios iniciales causados por el VPH de alto riesgo puede contribuir a la persistencia viral y la progresión de la enfermedad. Algunos agentes, como C. trachomatis y el VHS, causan inflamación local y podrían contribuir con el VPH en la progresión de la lesión cervical. Del mismo modo, otros microorganismos de importancia ginecológica como Gardnerella vaǵinalis y T. vaǵinalis, así como las especies de Mollicutes (bacterias sin pared) se incluyen en este contexto. Los Mollicutes pueden inducir la liberación de citoquinas como IL1 , IL-6 y TNF- $\alpha$ y quimioquinas, y causar una inflamación intensa; esta respuesta se ha sugerido como un posible factor de riesgo para el desarrollo de lesiones precancerosas (15). Los mecanismos propuestos a través de los cuales los agentes infecciosos podrían actuar como cofactores en la tumorigénesis asociada al VPH, incluyen las interacciones biológicas directas, como la modificación de la replicación y la transcripción del VPH, y los efectos indirectos, como la inflamación y el daño a la barrera epitelial que protege contra la infección por VPH $(15,16)$.

$U$. urealyticum ha sido identificado como un cofactor que interactúa con el VPH en el comienzo del cáncer cervical (17). Se ha reportado una alta asociación entre la infección por U. urealyticum y el grado de lesión cervical citológica (27\% para ASC-US, 35\% para LIEBG y $45 \%$ para LIEAG), así mismo una prevalencia significativamente menor (19\%) de positividad para este agente infeccioso en muestras provenientes de mujeres asintomáticas para inflamación cervicovaǵinal, y con citología y colposcopia negativas para lesión de cuello uterino. Igualmente, se ha reportado una asociación interesante de VPH con $U$. urealyticum en pacientes con citología vaginal positiva para LIEAG (83\%), mucho más alta que la observada en pacientes con citología vaginal ligeramente anormal o normal (56\% para ASC-US, 49\% para LIEBG y 40\% para citología normal) (16).

La búsqueda de microorǵanismos, mediante reacción en cadena de la polimerasa (PCR) para detectar microorganismos genitales y VPH ha sido reportada en mujeres con lesiones del cuello uterino, obteniéndose que un $85,5 \%$ de los casos con lesiones eervicales han sido positivos para infeceión con VPH. El ADN viral se detectó en $24,5 \%$ de las lesiones de bajo grado (LIEBG / NIC 1), en $26,4 \%$ de las lesiones de grado intermedio (NIC 2) y en $49,1 \%$ de las lesiones de alto grado (LIEAG; NIC 3 / carcinoma in situ). Otros microorganismos patógenos como $T$. vaǵinalis fueron encontrados en $61,3 \%$ de las mujeres con lesiones cervicales, quienes tuvieron mayor riesgo a este tipo de lesión relacionado con la presencia de este agente. $G$. vaginalis, aǵente asociado a vaǵinosis, se detectó en 91,9\% de las mujeres con lesiones cervicales, evidenciándose una asociación positiva y una detección mayor en casos de LIEAG (15).

Estudios han informado la presencia de infección por VHS-1 y VHS-2 en pacientes positivos para el ADN del VPH, que presentaban una zona de transformación anormal grado 1 en el examen colposcópico. Hay reportes de una fuerte evidencia del VHS2 como cofactor del VPH para aumentar el riesgo de desarrollar carcinoma cervical invasivo: la seropositividad al VHS-2 fue significativamente mayor entre los pacientes con carcinoma invasivo de células escamosas 
$(44,4 \%)$ o adenocarcinoma, o carcinoma de células adenoescamosas, que entre los sujetos control $(25,6 \%)$, mientras que entre las mujeres VPH positivas, la seropositividad al VHS-2 se asoció con un mayor riesgó de tal neoplasia (16).

Lesiones preinvasoras e invasoras del cuello uterino y cáncer cervical (CC)

En 1970, zur Hausen propuso que el CC podría ser causado por infecciones con el virus identificado en los condilomas acuminados (18); posteriormente, en el año 2009, demostró la presencia del genoma de VPH en tejido de CC (19). La infección cervical por genotipos VPH de alto riesǵo oncogénico (VPH AR), está estrechamente ligada al diagnóstico de lesiones pre-invasoras; todos los casos de CC invasivo diagnosticados alrededor del mundo, contienen ADN de los mismos 13 genotipos de VPH AR (20).

Existe evidencia sólida que relaciona la infección por VPH con la oncogénesis directa inducida fundamentalmente por los genotipos 16 y 18 (21-24); por lo tanto, dichas infecciones son consideradas el principal factor de riesgo asociado al desarrollo de LIEAG, y a la producción de cáncer invasivo de células escamosas, estimándose que aproximadamente entre el $10 \%$ y $20 \%$ de las mujeres infectadas por VPHAR, eventualmente mostrarán la progresión de lesiones intraepiteliales de bajo grado a las de alto grado y a CC (25).

Así mismo, se han identificado numerosos cofactores asociados al riesgo de adquisición de infecciones por VPH, y su progresión a lesiones cervicales premalignas y malignas, tales como otras ITS, el uso de anticonceptivos orales por más de 5 años, el hábito tabáquico y la elevada paridad $(26,27)$. Según reportes de la Orǵanización Panamericana de la Salud (OPS) para el año 2018, 72.000 mujeres fueron diagnosticadas de cáncer cérvico uterino y casi 34.000 fallecieron por esta enfermedad en la reǵión de las Américas. Por otro lado, datos actuales de la agencia internacional para la investigación del cáncer de la OMS, publicado en GLOBOCAN
2018, reportan que el CG representa el cuarto tipo de cáncer más común en la población femenina, constituyendo una causa importante de morbilidad y mortalidad con una incidencia de 569.847 nuevos casos $(6,6 \%)$. En cuanto a la región latinoamericana, es el tercer tipo de cáncer más común en la población femenina, con una incidencia de 39.581 nuevos casos $(7,4 \%)$ y, en Ecuador se encontró, para ese mismo año 160.012 casos, representando un $10,6 \%$ de los cánceres en la mujer ecuatoriana $(28,29)$.

Generalmente, el 90\% de las infecciones por VPHAR son autolimitadas y regresan espontáneamente meses después de su aparición. Sin embargó, cerca del 10\% de los casos pueden progresar a una infección transformante (30). El principal evento molecular que explica la progresión de las lesiones preneoplásicas de alto grado a un cáncer invasivo es el aumento sustancial de la expresión desregulada de los dos, bien caracterizados, oncogenes virales e6 y e7, que codifican oncoproteínas para iniciar y mantener el crecimiento neoplásico de las células epiteliales basales infectadas. Ambas oncoproteínas virales interactúan con una variedad de factores celulares implicados en la regulación y puntos de control del ciclo celular, así como de la maquinaria encargada de la muerte celular. Además, las oncoproteínas interfieren con la síntesis ordenada de los centrosomas, dando lugar a figuras de mitosis multipolares y distribución desequilibrada de los eromosomas durante la mitosis, una característica distintiva de la inestabilidad cromosómica (30).

La desregulación de la expresión de genes virales en los carcinomas de cuello uterino se ha asociado con la integración del genoma del VPH al ADN del huésped. El desarrollo de células malignas parece estar estrechamente relacionada con la generación de clones de células transformadas con copias del genoma integrado. Por eso, la integración viral es un elemento clave para el progreso hacia la carcinogénesis cervical (30). 
El ADN del VPH se puede encontrar en el material cervical como forma episomal (libre en el núcleo celular), inteǵrado (unido al genoma humano), o de ambas formas (forma mixta). En LIEBG, la mayoría de los genomas de VPH se mantienen bajo la forma episomal, mientras que en LIEAG y carcinomas, se encuentra un número elevado de genomas de VPH integrado en el genoma del huésped. Sin embargo, la frecuencia de integración genómica es sustancialmente más baja en las lesiones precancerosas cervicales de alto grado, en comparación con el estado de cáncer cervical, y es casi nula en las lesiones precancerosas de bajo grado. Diferentes estudios han reportado hasta un $88 \%$ del ADN de VPH integrado en CC (30).

\section{Clasificación de las lesiones premalig- nas del cuello uterino o Pre-Cáncer \\ Organización Mundial de la Salud (OMS)}

Las lesiones cervicales se pueden clasificar en displasia, carcinoma in situ (CIS), y cáncer invasivo. Así mismo, la displasia cervical se puede clasificar en leve, moderada y grave, en función del grado de implicación; es decir, la relación entre el grosor del epitelio cervical anormal y el espesor del epitelio completo (31).

\section{Clasificación de la neoplasia intraepi- telial cervical NIC \\ En 1968 se introdujo el término de} neoplasia intraepitelial cervical (NIC) para denotar las múltiples posibilidades de atipia celular confinada al epitelio. La NIC se dividió en los grados 1, 2 y 3 . NIC 1 correspondía a la displasia leve, NIC 2 a la displasia moderada y NIC 3 a la displasia grave y al carcinoma in situ. Se consideró que las lesiones de alto grado eran precursoras del cáncer invasor. Puede tomar años para que la displasia se convierta en carcinoma in situ o cáncer microinvasor, pero una vez que se da el proceso, el cáncer puede convertirse rápidamente en invasor y diseminarse a los ganglios linfáticos, tejidos cercanos $\mathrm{u}$ otros órgaanos como la vejiǵa, los intestinos, el hígado o los pulmones (31).

Clasificación de la citología cérvico vagiinal según el sistema Bethesda

En diciembre de 1988, el Instituto Nacional del Cáncer patrocinó un taller para desarrollar un sistema uniforme para clasificar la citología cérvico vaǵinal. «El sistema de Bethesda» conocido en el año 2001, es una clasificación que se refiere a la ampliación nuclear de las células glandulares, hipercromasia y/o anomalías arquitectónicas; así, clasifica las anomalías de las células escamosas en las siguientes categorías:

1. Células escamosas atípicas o «Atypical Squamous Cell» (ASC), que incluyen las lesiones con varias anormalidades sugestivas de lesiones escamosas intraepiteliales «Squamous Intraepithelial Lesions» (SIL) o su equivalente (LIE).

2. Bajas lesiones escamosas intraepiteliales «Low Squamous Intraepithelial Lesions» (LSIL) o (LIEBG), que abarca los cambios celulares asociados con el VPH y la displasia leve o NIC1.

3. Altas lesiones escamosas intraepiteliales «High Squamous Intraepithelial Lesions» (HSIL) o (LIEAG) incluye la displasia moderada o NIC2 y la displasia severa como NIC3.

Una de las modificaciones hechas, después de la primera reunión, fue la división del diaǵnóstico descriptivo: el diagnóstico de células escamosas atípicas de significado indeterminado "Atypical Squamous Cells of Undetermined Signnificance» (ASCUS) y de células glandulares atípicas de significado indeterminado «Atypical Glandular Cells of Undetermined Significance» (AGUS) (31).

\section{Microbioma Vagino Cervical}

El estudio de la microbiota vaginal es un área de estudio en pleno desarrollo. Con la llegada de las técnicas moleculares y las técnicas de secuenciación masiva se ha logrado la caracterización del gen ARNr 16S, que ha permitido determinar mejor la com- 
posición y comportamiento de las comunidades microbianas presentes en la vagina (32). Este hecho puede dar claridad entre la interacción de las células epiteliales que componen el microambiente vaginal, los elementos del sistema inmune asociada a esta mucosa, las alteraciones de la microbiota y la instauración de una infección transmitida por vía sexual. Por ello, definir la microbiota saludable es un reto, ya que la agrupación de comunidades parece ser un objetivo móvil con variabilidad a través del ciclo menstrual de la mujer y también de la edad reproductiva $(32,33)$.

La primera caracterización microbiológica de la vagina fue llevada a cabo por Döderlein (34), describiendo que los Lactobacillus son los microorganismos dominantes en dicho hábitat. Estas bacterias se caracterizan por tener una morfología alargada y al campo visual del microscopio se observan como rectas a curvadas e incluso espiraladas. Desde el punto de vista metabólico, son bacterias anaerobias aerotolerantes y se agrupan como bacterias productoras de ácido láctico, siendo fermentadores de los azúcares. Las especies más frecuentes a encontrar son L. crispatus, L. gasseri y L. jensenii; y otros autores refieren la presencia de $L$. iners y $L$. vaginalis. Considerando la composición bioquímica del moco vaginal que es abundante en ǵlucosa y distintos aminoácidos, debido a la presencia de estos nutrientes, se promueve la colonización persistente en la vagina por bacterias de la misma microbiota autóctona. Sin embargó, existen otros factores que contribuyen al establecimiento de los Lactobacillus, como las variaciones de las células epiteliales y el perfil hormonal; así como la composición, cantidad y viscosidad del moco vaginal durante las distintas etapas de la vida (35).

A partir del nacimiento, la vagina se colonizará con estos microorganismos durante el paso por el canal del parto. Luego, en las niñas premenárquicas, la microbiota residente será el resultado de la contaminación proveniente de la piel y del intestino.
Después, al inicio de la pubertad, la secreción vaginal que es rica en nutrientes facilitará la colonización por Lactobacillus. Los productos metabólicos provenientes de la fermentación actuarán en la prevención del establecimiento de agentes contaminantes intestinales y en el mantenimiento del control de la proliferación excesiva de Gardnerella vaginalis, Candida albicans y otros patógenos. El efecto protector de la microbiota es tan específico que en muchas mujeres sanas sólo se aíslan Lactobacillus de su vaǵina (35).

Finalmente, cuando la mujer alcanza la menopausia, la interrupción del ciclo estrogénico se acompaña de una disminución del volumen del exudado vaginal y de los nutrientes disponibles, lo que provoca la disminución de la densidad microbiana hasta el 1\%, ahora con predominio de bacterias intestinales y de la piel. Sin embargó, el 50\% de las mujeres pueden conservar una población apreciable de Lactobacillus (35).

En la vagina de mujeres sanas se pueden encontrar varios géneros bacterianos, tales como: cocos y bacilos grampositivos anaerobios aerotolerantes como Streptococcus; cocos y bacilos grampositivos anaerobios facultativos como Corynebacterium, Gardnerella y Staphylococcus, fundamentalmente $S$. epidermidis; bacilos gramnegativos anaerobios facultativos como Escherichia, Klebsiella, Proteus; gramnegativas sin pared celular como Mycoplasma hominis y Ureaplasma; bacilos y cocos grampositivos anaerobios estrictos como Atopobium, Peptococcus, Peptostreptococcus, Clostridium, Bifidobacterium, Propionibacterium, Eubacterium; y bacilos gramnegativos anaerobios estrictos como Bacteroides y Prevotella. Es importante resaltar, que la mayoría de estos géneros se encuentran principalmente en el hábitat intestinal, y que pueden aparecer esporádicamente en la vaǵina, lo que sugiere que en esta mucosa son transeúntes más que colonizadoras (34).

El aspecto fundamental de la presencia y actividad funcional de los Lactobacillus 
viene dado por la producción de sustancias antibacterianas como péptidos y metabolitos, tales como el peróxido de hidrogeno y el ácido láctico, que poseen una importante actividad microbicida sobre especies bacterianas patógenas, actuando como primera línea de defensa al establecer un pH bajo de 4.0. Estos elementos evitan la adherencia, el crecimiento bacteriano desregulado y la formación de biopelícula por patobiontes y patógenos. También se ha descrito que la interacción entre los Lactobacillus y el epitelio vaginal da como producto la formación de una biopelícula que protege frente a la colonización por microorganismos patobiontes, así mismo induce la coagregación de patógenos potenciales. Este efecto se ha dilucidado mejor al identificar la producción de glicoproteínas dependientes de $\mathrm{Ca}^{2++}$ y lipoproteínas exocelulares por estas células bacterianas (34).

Las especies que son protectoras pueden inhibir el crecimiento de patógenos a través de la expresión de proteínas bactericidas y bacteriostáticas tales como bacteriocinas, que han evolucionado como resultado de la competencia de los ecosistemas. Gasserin es un ejemplo de una bacteriocina de este tipo que se aisló por primera vez de $L$. gasseri, pero desde entonces se ha encontrado que es producida por otras cepas de $L$. crispatus y L. reuteri. Los biosurfactantes son otro grupo de péptidos excretados por bacterias que pueden alterar la tensión superficial y, por lo tanto, la adhesión bacteriana, impidiendo la formación de biopelículas asociadas con el crecimiento excesivo de anaerobios patógenos, en particular G. vaginalis. Recientemente, se ha demostrado que las cepas de L. crispatus excretan la adhesina del epitelio del Lactobacillus (LEA), un compuesto que media la adhesión a la mucosa intestinal y genital, pero además inhibe la adhesión de G. vaginalis (36).

Estudios moleculares han demostrado que no todos los Lactobacillus que se encuentran en la mucosa cervicovaginal son iguales. La especie $L$. crispatus coexiste con otros microorganismos y se asocia con un perfil inmune cervicovaginal antiinflamatorio protegiendo a las mujeres de desarrollar disbiosis anaeróbica. En contraste, L. iners parece no proteger a las mujeres del desarrollo de disbiosis anaeróbica y, a menudo, aumenta conjuntamente con anaerobios asociados con vaginosis bacteriana y patobiontes como Streptococcus, Staphylococcus $\mathrm{y}$ enterobacterias (37).

Existen numerosos factores exógenos que han sido estudiados para dilucidar como influyen sobre la microbiota vaginal. De particular interés se han estudiado los anticonceptivos hormonales y el consumo de cigarrillos, ya que ambos se han asociado con el desarrollo del cáncer cervical. El uso combinado de anticonceptivos orales se asocia con un aumento en el nivel de citoquinas inflamatorias en el cuello uterino. La fuente de estas citoquinas es desconocida, pero se cree que la microbiota influye sobre este ambiente inflamatorio. A pesar del patrón inflamatorio, la misma inflamación aguda puede actuar como agente protector contra la adquisición de agentes productores de ITS, incluido el VPH; sin embargoo, la exposición continua y crónica a la inflamación es tóxica para las células por el daño al genoma presente en las células epiteliales (33).

VPH y microbioma cérvico vaginal en el desarrollo de lesiones preinvasoras e invasoras del cuello uterino

En la actualidad, las técnicas ómicas han permitido dilucidar de mejor manera, el papel de la microbiota que habita en el humano y su comportamiento en el mantenimiento del estado de salud o en el desarrollo de determinadas patologías, tales como el cáncer. Cuando no se mantiene el equilibrio de esta relación simbiótica, ocurre un desequilibrio bioquímico y celular que permite la actividad y proliferación de microorganismos patógenos que tienen la capacidad de modular importantes vías de señalización celular en el huésped, promoviendo el crecimiento aberrante y la inmortalización de

Vol. 60(4): 336 - 351, 2019 
determinados tipos de células en los sitios de infección (38).

De esta forma, la disbiosis puede conllevar a la oncogénesis y la progresión de tumores en múltiples niveles, como resultado de los efectos directos de microorganismos oncogénicos o sus productos, así como las alteraciones mediadas por los metabolitos circulantes o factores tróficos, tales como los factores de crecimiento, los cuales favorecen el crecimiento tumoral y el perfil alterado de citoquinas que, a su vez, induce efectos proinflamatorios e inmunosupresores y pueden subvertir la inmunovigilancia contra el cáncer (38).

Estudios recientes han descrito que la alteración de la microbiota cervical podría conllevar al condicionamiento de un microambiente propicio para el desarrollo de lesiones neoplásicas cervicales bajo ciertas infecciones. Los factores mecánicos como las microabrasiones generadas durante las relaciones sexuales y los factores biológicos como los cambios en las comunidades bacterianas, la elevación del pH, la vaǵinosis bacteriana y las ITS pueden alterar el microambiente cérvicovaginal al cambiar el perfil de citoquinas y, por ende, permitir la persistencia de microorganismos de vida intracelular, como es el caso del VPH, promoviendo al desarrollo de displasia cervical (38-40). Una microbiota cervical alterada puede ser un factor importante para la adquisición, reactivación o eliminación tardía de la infección por VPH e incluso la gravedad de la NIC (40).

Algunos investigadores han reportado el papel que esta relación infecciosa puede tener en la progresión de lesiones neoplásicas, sugiriéndose que las alteraciones en el microbioma cervical pueden desempeñar un papel importante en el establecimiento y progresión del cáncer, específicamente relacionado a la presencia de bacterias asociadas a vaǵinosis bacteriana como la $G$. vaǵinalis.

Romero y col. (41) estudiaron 177 muestras de raspado de cérvix, de las cuales 104 pertenecieron a mujeres sin alteraciones citológicas ni colposcópicas y 73 muestras de lesiones precursoras con antecedentes de infección por VPH. Todas estas muestras fueron sometidas a detección de secuencias de G. vaginalis y VPH por medio de PCR. Los resultados mostraron una prevalencia mayor de VPH en las muestras con lesiones cervicales precursoras y un poco más del $30 \%$ de las muestras sin lesión resultaron positivas para este virus. Además, prácticamente todas las muestras tuvieron secuencias de G. vaginalis, sin asociación con la presencia viral. Este hallazgo podría indicar que este microorganismo sería parte del microbioma cervical en la población, por lo que es de especial importancia reconsiderar el papel patógeno de esta bacteria.

Amorin y col. (15) reportaron la coinfección de $G$. vaginalis y VPH en muestras cervicales, presentándose como un cofactor de riesgo para lesiones de cuello uterino. También detectaron G. vaginalis en 91,9\% de las mujeres que tenían lesiones cervicales y una asociación positiva con la presencia de lesión, mostrando una mayor detección en LIEAG.

Se cree que la respuesta inflamatoria causada por la gran carǵa de microorganismos en el sitio de la infección puede conducir a daño celular sugestivo de lesiones cervicales, como se ha observado para otros microorganismos. Maǵaña y col. (42) realizaron un estudio sobre la prevalencia de patógenos asociados a VPH en muestras cervicales de consultas de rutina, encontrando G. vaginalis en un $25,9 \%$. La infección por VPH oncogénicos se asoció significativamente con $G$. vaginalis y esta última presentó signnificancia con LIEBG.

Un estudio llevado a cabo por Di Paola y col. (43), reflejó algunos cambios en las comunidades de la microbiota cérvicovaginal que podrían facilitar la infección por el VPH y contribuir a la persistencia viral y, por ende, al desarrollo del cáncer. Este evento ocurre inicialmente por la depleción en masa de los Lactobacillus y el aumento en la diversidad de otros microorganismos que poseen características no protectoras del microambiente 
corporal donde están ubicados. El análisis de 55 muestras cérvicovaginales positivas para el diagnóstico de VPH de alto riesgo, permitió definir poblaciones bacterianas como estados de comunidad microbiana (ECM), obteniendo un total de cuatro subgrupos (I - IV). El subgrupo ECM IV contó con géneros bacterianos como Gardnerella, Prevotella, Megasphoera y Atopobium; bacterias que están frecuentemente relacionadas con el desarrollo de vaginosis bacteriana (VB).

En este mismo sentido, el género Atopobium se detectó con mayor frecuencia en el grupo de bacterias asociadas a la infección persistente del VPH, en comparación con los otros grupos. Así mismo, se detectó que el gen que codifica la sialidasa de Gardnerella vaginalis estaba implicado en la formación de biopelículas. Este elemento genético se encontró cuantitativamente más elevado en el grupo que presentaba infección persistente con VPH. Con base en estos datos, los autores consideraron el ECM IV, como un factor de riesgo para la persistencia del VPH y, proponen la detección del genoma de Atopobium spp y la pesquisa del gen sialidasa de G. vaǵinalis como marcadores microbianos para predecir la persistencia viral del VPH (43).

Otros autores han realizado estudios con la finalidad de determinar la composición de las comunidades microbianas y su papel en la carcinogénesis y potenciación de la infección por VPH. Zhang y col. (44) analizaron pacientes con epitelios cervicales normales y con NIC; se buscó establecer las asociaciones directas e indirectas entre la microbiota y el estadio de NIC. Se observó que los géneros más importantes encontrados fueron Lactobacillus (L. iners y L. crispatus) y Gardnerella. Los análisis revelaron que las muestras positivas para VPH tenían Streptococcus agalactiae, Bacteroides fragilis, Pseudomonas stutzeri y Peptostreptococcus anaerobius, mientras que en las muestras negativas para VPH hubo abundancia de Lactobacillus delbrueckii (44). Con respecto a la asociación de los microorganismos con el grado de NIC, se detectó abundancia de Photobacterium damselae, Lactobacillus jensenii y Atopobium vaginae en las muestras con NIC1, mientras que en las muestras con NIC2, se detectó mayor abundancia de $L$. crispatus, Streptococcus agalactiae, Bacteroides fragilis y Campylobacter ureolyticus. Además, se observaron efectos indirectos de P. stutzeri, B. fragilis, L. delbrueckii, A. vaginae y $S$. agalactiae mediando el estado de NIC provocado por la infeceión con VPH oncogénico (44).

En otro trabajo (39) se analizó la microbiota cervical de 70 mujeres con NIC y 50 mujeres de control mediante pirosecuenciación estudiando el gen ARNr 16S. En los resultados se encontró, mediante el análisis de mapas de calor a nivel de especie, que la microbiota cervical se distribuyó en cuatro grupos. Los Lactobacillus predominaron en el grupo I; A. vaginae, Prevotella bivia, Lactobacillus fornicalis, Pseudomonas poae y $G$. vaginalis fueron dominantes en el grupo II; $L$. iners y $L$. crispatus fueron dominantes en el grupo III y L. iners, A. vaginae, P. bivia y Prevotella amnii fueron abundantes en el grupo IV. En la mayoría de las mujeres negativas para infección con VPH se reportó $L$. iners y L. crispatus como miembros dominantes. El patrón microbiano de riesǵo para NIC se caracterizó por un predominio de $A$. vaginae, L. iners y G. vaginalis, y una eseasez concomitante de L. crispatus.

La infección por VPH junto a la coinfección con $G$. vaginalis, se han asociado fuertemente con la presencia de L. iners, sugiriendo que hay especies que podrían jugar un papel distintivo de la función ecológica y carcinogénesis cervical; sin embargo, L. crispatus se asocia con un bajo riesgo, figurando como protector contra el desarrollo de lesiones precancerosas y cancerosas (39).

Distintas publicaciones $(33,39,40,43)$ sugieren que $L$. gasseri se encuentra elevado en mujeres infectadas por VPH; sin embargo, existen estudios que avalan que las poblaciones microbianas, especialmente la de los lactobacilos, disminuyen durante la infección

Vol. 60(4): 336 - 351, 2019 
por VPH y, junto a la asociación con Atopobium, reducen la posibilidad de negativizar la infección cervical.

El papel prejudicial de $L$. iners se ha relacionado con el agotamiento del ǵlutatión reducido, a diferencia de $L$. crispatus y $L$. jensenii, que se asocian con un aumento de los niveles de glutatión, esto implica que la colonización de $L$. iners produce niveles más altos de estrés oxidativo en el microambiente cervical. Estudios donde han empleado técnicas de secuenciación de nueva generación, proponen la detección de Sneathia sanguinegens, Anaerococcus tetradius, Peptostreptococcus anaerobius como mareador microbiológico indirecto de la infección por VPH y directo de la enfermedad cervical. De igual modo, la presencia de Fusobacterium condiciona un microambiente elevado en IL-4 y TGF- $\beta 1$, propicio para la progresión de lesiones neoplásicas cuando hay infección por VPH (33). Así mismo, la presencia de $G$. vaǵinalis, A. vaǵinae y Prevotella spp, no solo favorecen la persistencia del VPH, sino también la infección genital por C. trachomatis $(44,45)$.

Mitra y col. (37) describen que el aumento de la diversidad de la microbiota vaginal combinada con la reducción de Lactobacillus spp participa en la adquisición y persistencia del VPH y en el desarrollo del precáncer cervical y el cáncer. Sin embargo, no se conoce cómo exactamente la microbiota vaginal podría desempeñar un papel, y se requieren más estudios. Se reconoce que los Lactobacillus spp previenen la colonización de especies bacterianas asociadas a la vaginosis bacteriana, mediante el mantenimiento de un pH bajo y la producción de bacteriocinas; esto es importante para el mantenimiento de la función de la barrera epitelial cervical que inhibe la entrada del VPH a los queratinocitos basales (37).Cuando los anaerobios estrictos asociados con VB pueden colonizar, producen enzimas y metabolitos que comprometen esta barrera, facilitando la entrada del VPH, también actúan sobre varias vías celulares que permiten una infección viral persistente y productiva, así como el desarrollo y la progresión de la enfermedad (37).

El pH vaǵinal superior a 5 se asocia significativamente con un aumento del 10-20\% en el riesgo de positividad al VPH en mujeres premenopáusicas. Se sabe que la proteína E5 del VPH, responsable de la transformación viral, es particularmente susceptible a un pH bajo, que es un mecanismo plausible para esta observación. Aunque un ambiente de $\mathrm{pH}$ bajo promovido por el ácido láctico puede considerarse generalmente protector, la infección del VPH y el desarrollo de la NIC pueden verse influidos, adicionalmente, por la estructura química de la propia molécula del ácido láctico. El ácido láctico, como compuesto carbonado, es un producto generado de la heterofermentación por bacterias, liberándose en isómeros con D (dextrógiro) y L (levógiro), siendo el primero producido predominantemente por L. jensenii, L. crispatus y L. gasseri. Sin embarǵo, el isómero L del ácido láctico es producido por el epitelio vaginal, $L$. iners y varios anaerobios asociados con disbiosis (37).

Las mujeres con ECM III y IV, por lo tanto, exhiben una mayor proporción de $\mathrm{L}$ que de D-lactato, lo que puede conducir a un aumento de la expresión del inductor de metaloproteinasa de matriz extracelular y la activación de la metaloproteinasa de matriz 8 (MPM8); esta expresión podría alterar la integridad cervical y facilitar la entrada del VPH a los queratinocitos basales. Recientemente, se ha demostrado que las altas concentraciones de D-lactato producidas por la microbiota dominante de L. crispatus, aumentan la viscosidad del moco cérvicovaginal, así como también su potencial de atrapamiento de partículas virales (37).

La disbiosis provoca la interrupción de las proteínas clave del citoesqueleto vaginal epitelial, con un aumento de la muerte celular, lo que implica daño y descamación de las células epiteliales; este cambio podría facilitar la entrada del VPH en las células epiteliales basales de la zona de transformación cer- 
vical, donde el virus prospera y se desarrolla la NIC (37).

La VB está asociada con una mayor diseminación del VIH y el VHS-2, y se ha demostrado que G. vaginalis, en particular, induce la replicación del VIH in vitro. Por lo tanto, es plausible que pueda existir un mecanismo similar para el VPH y que la disbiosis, la escasez de Lactobacillus spp o una combinación de los dos, pueda crear un ambiente que promueve el ciclo de vida viral, la persistencia de la infección y, en última instancia, el desarrollo de la displasia (37).

Las sialidasas son un grupo de enzimas que degradan la mucina producida principalmente por Prevotella y Bacteroides spp y se encuentran en niveles significativamente más altos en mujeres con VB. La disbiosis también puede provocar una disminución de la producción de moco y una subsiguiente disminución del atrapamiento viral mediante la captura de anticuerpos, así como un aumento de la exposición del epitelio cervical. También existe evidencia de que la inflamación juega un papel importante en la enfermedad cervical inducida por la disbiosis. Los estudios clínicos han demostrado que los niveles de citoquinas proinflamatorias vaginales son más altos en mujeres con disbiosis y pueden provocar una inflamación crónica, un factor bien conocido en la carcinogénesis de numerosos tejidos en el cuerpo (37).

También se ha demostrado que la disbiosis produce niveles más altos de estrés oxidativo, que puede generar especies reactivas de oxígeno (ROS), las cuales posteriormente causan roturas de $\mathrm{ADN}$ de doble cadena tanto en el episoma del VPH como en el genoma del huésped, lo que ayuda a la integración del mismo y, en última instancia, a la transformación neoplásica. Actualmente, no está claro si las comunidades microbianas disbióticas vaginales actúan en sinergia con el VPH para manipular sus objetivos celulares, como p53, pRB, survivina y la telome- rasa de transcriptasa inversa en humanos, o si esto ocurre de forma independiente. Sin embargoo, la evidencia apunta hacia la probabilidad de que especies particulares tengan un papel patológico en la adquisición y persistencia del VPH, en lugar de la disbiosis en su conjunto (44).

G. vaginalis se encuentra comúnmente en ECM IV, y se presenta a menudo en relativa abundancia en la vagina de mujeres adolescentes, cuyo cérvix es más susceptible a la infección por VPH en comparación con las mujeres mayores. Esto se correlaciona positivamente con la tasa de metaplasia escamosa. Es plausible que los niveles más altos de $G$. vaginalis puedan jugar un papel durante este período de mayor susceptibilidad. Sneathia spp se ha identificado con frecuencia en asociación con la positividad del VPH y con la NIC y el cáncer cervical (37).

Se ha reportado el uso de un método basado en PCR para mostrar que Leptotrichia amnionii (ahora llamada Sneathia amnii), se asocia a cáncer cervical, pero no con infección por VPH o NIC. La especie no es exclusiva de las mujeres con cáncer, lo que sugiere que puede desempeñar un papel en la carcinogénesis, en lugar de ocurrir como consecuencia de la enfermedad (37). Sneathia spp, perteneciente al género Fusobacterium, se ha implicado además en la carcinogénesis colorrectal a través de la activación de vías proinflamatorias e inhibición de la inmunocitotoxicidad. Fusobacterium spp produce FadA, un factor de virulencia que es capaz de activar la vía de señalización WNT. Las fusobacterias también están implicadas en la modulación de las vías inmunomoduladoras. Por ejemplo, se ha demostrado que los niveles de ADN de F. nucleatum son inversamente proporcionales al recuento de las células TCD3+ en la mucosa colónica, lo que es interesante dado que se ha observado una señal y función aberrante de estas células en los cánceres de cuello uterino con la enfermedad recurrente (Fig. 1) (37).

Vol. 60(4): 336 - 351, 2019 

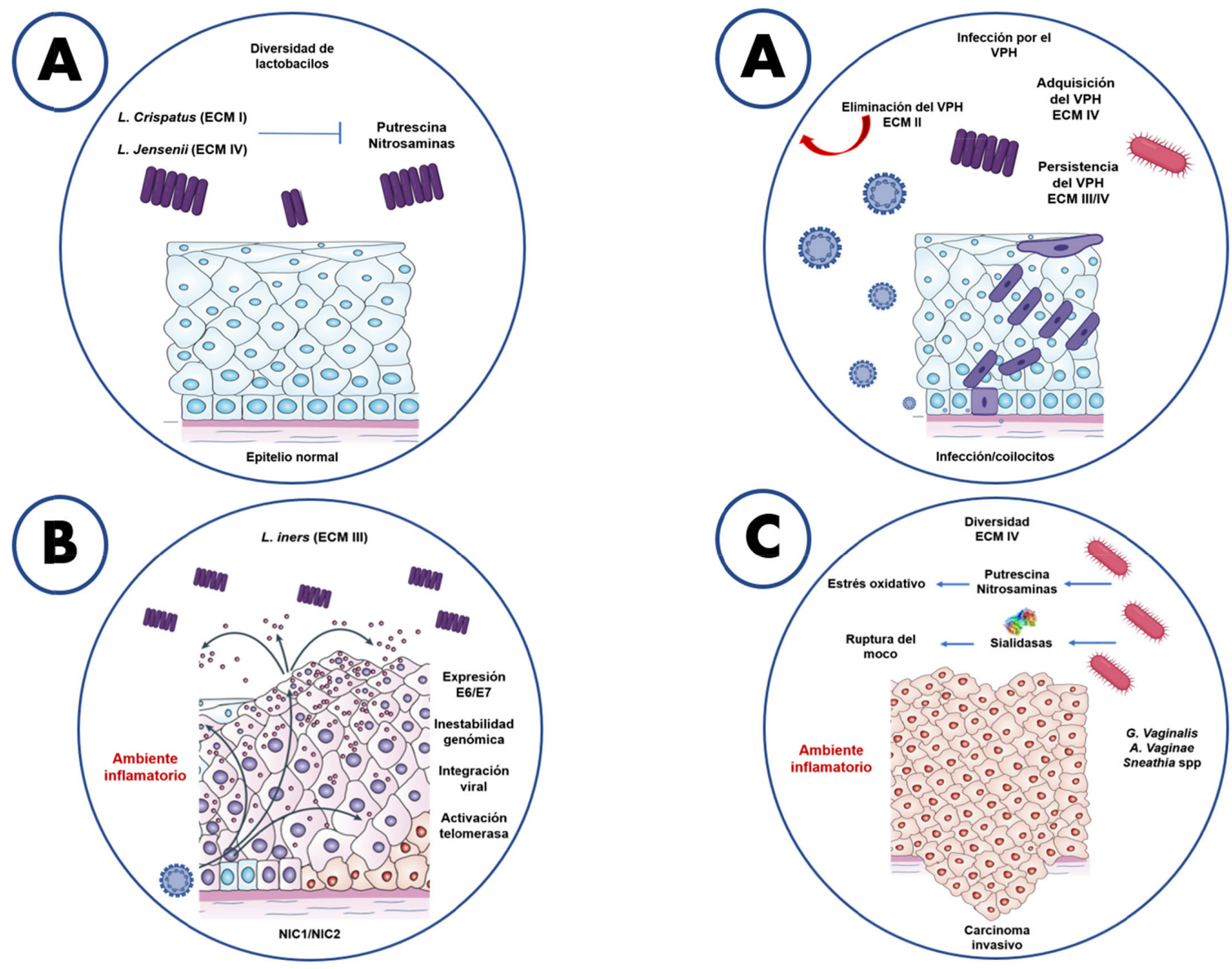

Fig. 1. Resumen de los mecanismos posibles que asocian a la microbiota vaginal con la enfermedad cervical. A Una estructura microbiota vaǵinal parece estar asociada con la adquisición y persistencia de la infección por VPH, y el ECM II en particular se asocia con la eliminación más rápida de una infección aǵuda por VPH. B La disbiosis puede producir un entorno inflamatorio, que puede facilitar varios de los pasos necesarios en la transformación viral, incluida la expresión de E6 y E7, la inestabilidad genómica, la integración viral y la activación de la telomerasa, que son necesarias para la carcinogénesis. C Mayor diversidad con menos Lactobacillus spp; se ha asociado con el aumento de la severidad de la NIC. Las especies particulares asociadas con la microbiota vaginal de alta diversidad pueden producir sialidasas que causan la descomposición del moco, predisponiendo el epitelio cervical al daño tisular; así como la producción de aminas biológicas responsables del estrés oxidativo, un mecanismo clave en la carcinogénesis. Se ha demostrado que ciertas especies de Lactobacillus limpian estas aminas y, por lo tanto, su presencia puede reducir el riesǵo de daño oxidativo. L. iners no parece compartir muchos de los mecanismos de protección de otras especies de Lactobacillus, parece tener menor capacidad para prevenir la enfermedad cervical.

Existe la necesidad de estudios longitudinales adicionales para demostrar que los resultados de la enfermedad están influenciados por la composición de la microbiota vaginal y cervical. Además, es posible que solo ciertas cepas de una especie bacteria- na puedan proteger o promover procesos de enfermedades. Junto con la microbiota bacteriana, el viroma es ahora una nueva área de interés emergente. Aunque se sabe que el VPH es el agente etiológico en las patologías precancerosas y cancerosas del cuello 
uterino y del tracto genital inferior, otros géneros virales presentes en la vagina normal, junto al VPH, pueden estar involucrados en la progresión de la enfermedad. Por otra parte, existe conocimiento de una relación simbiótica entre las comunidades bacteriana y viral, que requiere de investigación adicional específica para el VPH y la patología cervical (37). Los estudios futuros deben explorar el vínculo causal entre la microbiota vaginal y el resultado clínico en muestras longitudinales de biobancos existentes (33).

Los datos revisados muestran claramente la importancia de una vigilancia epidemiológica, no solo para la detección y genotipificación de VPH, sino también para la identificación de otros microorganismos causantes de ITS que pueden actuar como cofactores en el desarrollo de lesiones cancerosas, y finalmente para el estudio de la microbiota cérvico vaginal, en el entendido de que la variación del entorno microbiológico puede facilitar la persistencia de la infección por VPH oncogénicos, y por ende el desarrollo de cáncer.

\section{REFERENCIAS}

1. Organización Mundial de la Salud. Infecciones de transmisión sexual. 2016; Consultado en: [En línea] 2016 [Citado el 18 de agosto del 2018] disponible en: http:// www.who.int/mediacentre/factsheets/ fs110/es/.

2. Garaycochea M, Pino R, Chávez I, Portilla J, Miraval M, Arguedas E, Linares P, Cabezudo E, Romero S, Espinoza M. Sexually transmitted infections in women living in a prison in Lima, Perú. Rev Peru Med Exp Salud Pública 2013; 30(3):423-427.

3. Organización Panamericana de la Salud (OPS). Guía de atención integral de las Enfermedades de Transmisión Sexual 2011. Consultado en: [En línea] 2011 [Citado el 18 de abril del 2018] disponible en: www. paho.org/ecu/index.php?option $=\mathrm{com}_{-}$ content \&view $=$ article\&id $=512$ : guia-atencion-integral-infecciones-transmision-sexual-2011\&Itemid $=972$.
4. Shew M, Fortenberry J, Tu W, Juliar B, Batteiger B, Qadadri B, Brown D. Association of condom use, sexual behaviors, and sexually transmitted infections with the duration of genital human papillomavirus infection among adolescent women. Arch Pediatr Adolese Med 2006; 160(2): 151-156.

5. Zhu H, Shen Z, Luo H, Zhang W, Zhu $X$. Chlamydia Trachomatis Infection-Associated Risk of Cervical Cancer: A Meta-Analysis. Medicine (Baltimore). 2016;95(13):e3077.

6. Samoff E, Koumans E, Markowitz L, Sternberg M, Sawyer M, Swan D, Papp J, Black C, Unger E. Association of Chlamydia trachomatis with persistence of high-risk types of human papillomavirus in a cohort of female adolescents. Am J Epidemiol 2005; 162(7): 668-675.

7. Knowlton A, Brown H, Richards T, Andreolas L, Patel R, Grieshaber S. Chlamydia trachomatis infection causes mitotic spindle pole defects independently from its effects on centrosome amplification. Traffic 2011;12(7):854-866.

8. Sun H, Wilde A, Harrison R. Chlamydia trachomatis inclusions induce asymmetric cleavage furrow formation and ingression failure in host cells. Mol Cell Biol 2011;31(24):5011-5022.

9. Kahesa C, Mwaiselage J, Wabinga HR, Ngoma T, Kalyango JN, Karamagii CA. Association between invasive cancer of the cervix and HIV-1 infection in Tanzania: the need for dual sereening. BMC Public Health 2008;8:262.

10. Holmes K, Bertozzi S, Bloom B, Jha P, Gelband H, DeMaria L, Horton S. Major Infectious Diseases: Key Messages from Disease Control Priorities. En: Holmes K, Stefano Bertozzi S, Bloom B, Prabhat Jha. Disease Control Priorities. ( $3^{\text {rd }}$ ed). Washington, DC: World Bank; 2017. P: 1-27.

11. Bruni L, Diaz M, Castellsagué $X$, Ferrer E, Bosch FX, de Sanjosé S. Cervical human papillomavirus prevalence in 5 continents: meta-analysis of 1 million women with normal cytological findings. $J$ Infect Dis 2010;202(12):1789-1799.

12. Chrysostomou A, Stylianou D, Constantinidou A, Kostrikis L. Cervical cancer screening programs in Europe: the transition towards HPV vaceination and

Vol. 60(4): 336 - 351, 2019 
population-based HPV testing. Viruses 2018;10(12):729.

13. Yanik EL, Napravnik S, Cole SR, Achenbach CJ, Gopal S, Olshan A, Dittmer DP, Kitahata MM, Mugavero MJ, Saag M, Moore RD, Mayer K, Mathews WC, Hunt PW, Rodriguez B, Eron JJ. Incidence and timing of cancer in HIV-infected individuals following initiation of combination antiretroviral therapy. Clin Infect Dis 2013;57(5):756-764.

14. Salters KA, Cescon A, Zhang W, Ogilvie G, Murray MC, Coldman A, Hamm J, Chiu CG, Montaner JS, Wiseman SM, Money D, Pick N, Hoǵg RS. Cancer incidence amonǵ HIV-positive women in British Columbia, Canada: Heightened risk of virus-related malignancies. HIV Med 2016;17(3):188-195.

15. Amorim A, Marques L, Campos G, Lobão T, De Souza Lino V, Cintra R, Andreoli M, Villa L, Boccardo E, Junior A, López R, Dos Santos D, De Souza G, Romano C, Timenetsky J. Co-infection of sexually transmitted pathogens and human papillomavirus in cervical samples of women of Brazil. BMC Infect Dis 2017;17(1):769.

16. Lukic A, Canzio C, Patella A, Giovagnoli M, Cipriani P, Frega A, Moscarini M. Determination of cervicovaginal microorganisms in women with abnormal cervical cytology: the role of Ureaplasma urealyticum. Anticancer Res 2006;26(6C):4843-4849.

17. Mitsuaki O, Jumpei K, Kaori O, Kenji K, Tadasi F, Natsuko S, Timothy C, Hiromi Y, Masahiko F. Cytological features associated with Ureaplasma Urealyticum in pap cervical smear. Asian Pac J Cancer Prev 2017; 18(8): 2239-2242.

18. Zur, H. Papillomaviruses in human cancers. Proc Assoc Am Physic 1999; 111(6): 581-587.

19. Zur, H. Papillomaviruses in the causation of human cancers-a brief historical account. Virology 2009; 384(2): 260-265

20. Burk R, Chen Z, Van Doorslaer K. Human papillomaviruses: genetic basis of carcinogenicity. Public Health Genom 2009; 12: 281-290.

21. Campbell K. The infectious causes of cancer. Nurs Times 2006; 102(33): 28-30.

22. Castellsagué $X$. Natural history and epidemiology of HPV infection and cervical cancer. Gynecol Oncol 2008; 110 (3 Suppl 2): S4-S7.
23. Gravitt P. The known unknowns of HPV natural history. J Clin Invest 2011; 121(12): 4593-4599.

24. Haghshenas M, Golini M, Rafiee A, Emadeian O, Shykhpour A, Ashrafi G. Prevalence and type distribution of high-risk human papillomavirus in patients with cervical cancer: a population-based study. Infect Agent Cancer 2013;8(1):20.

25. Haverkos H. Multifactorial etiology of cervical cancer: a hypothesis. Med Gen Med 2005; $7(4): 57$.

26. 26. Ferreiro M, Rodríguez M, Fernández J, Díaz J, Roye R. Análisis del comportamiento de las ITS en Venezuela durante los últimos 10 años. Dermatol Venez 2004;42(3): $38-42$.

27. Núñez J, Delgado M, González J, Mindiola R, Velásquez J, Conde B, Whitby D, Munroe $\mathrm{D}$. Prevalence and risk factors of human papillomavirus infection in asymptomatic women in a Venezuelan urban area. Invest Clin 2009; 50(2): 203-212.

28. Organización Panamericana de la salud (OPS). Cáncer Cérvicouterino. 2018; Consultado en: [En línea] 2019 [Citado el 1 de octubre del 2019] disponible en:https:// www.paho.org $/ \mathrm{hq} /$ index.php?option $=$ com_ content\&view $=$ article\&id = 5420:2018-cervical-cancer\&Itemid=3637\&lang $=$ es.

29. Agencia Internacional para la Investigación del Cancer/OMS. The Global Cancer Observatory (Globocan) 2018 World/ Americas región/Ecuador. Consultado en: [En línea] 2018 [Citado el 1 de octubre del 2019] disponible en: http://ǵco.iarc. $\mathrm{fr} /$ today/data/factsheets/populations/900world-fact-sheets.pdf.

30. Vinokurova S, Wentzensen N, Kraus I, Klaes R, Driesch C, Melsheimer P, Kisseljov F, Dürst M, Schneider A, von Knebel Doeberitz M. Type-dependent integration frequency of human papillomavirus genomes in cervical lesions. Cancer Res 2008;68(1):307-313.

31. Sellors J, Sankaranarayanan R. La colposcopia y el tratamiento de la neoplasia intraepitelial cervical. Manual para principiantes. Francia: Centro Internacional de Investigaciones sobre el Cáncer; 2003. p. 13-19.

32. Muhleisen AL, Herbst-Kralovetz MM. Menopause and the vaginal microbiome. Maturitas 2016;91:42-50. 
33. Kyrgiou M, Mitra A, Moscicki AB. Does the vaginal microbiota play a role in the development of cervical cancer? Transl Res 2016;179:168-182.

34. Martína R, Soberóna N, Vázqueza F, Suáreza J. Vaginal microbiota: composition, protective role, associated pathologies, and therapeutic perspectives. Enferm Infece Microbiol Clin 2008; 26 (3): 125-183.

35. Álvarez G, Suárez E, Rodríguez JM, Pérez J. La microbiota en la mujer; aplicaciones clínicas de los probióticos. Nutr Hosp 2015;32(Supl. 1):56-61.

36. Van de Wijge $\mathbf{J}$. The vaginal microbiome and sexually transmitted infections are interlinked: Consequences for treatment and prevention. PLoS Med 2017;14(12):e1002478.

37. Mitra A, MacIntyre DA, Marchesi JR, Lee YS, Bennett PR, Kyrgiou M. The vaǵinal microbiota, human papillomavirus infection and cervical intraepithelial neoplasia: what do we know and where are we going next? Microbiome 2016;4(1):58.

38. Avilés J, Yu G, Torres P, Madrid M, Torres J. On the search to elucidate the role of microbiota in the genesis of cancer: The cases of gastrointestinal and cervical cancer. Arch Med Res 2017;48(8):754-765.

39. Oh H, Kim B, Seo S, Kong J, Lee J, Park S, Hong K, Kim H, Kim M. The association of uterine cervical microbiota with an increased risk for cervical intraepithelial neoplasia in Korea. Clin Microbiol Infect 2015;21(7):674.e1-9.

40. Champer M, Wong AM, Champer J, Brito IL, Messer PW, Hou JY, Wright JD. The role of the vaginal microbiome in gynaecological cancer. BJOG 2018;125(3):309-315.
41. Romero P, Bandala C, Jiménez J, Valdespino M, Rodríguez M, Gama R, Bandera A, Mendoza M, Taniguchi K, Marrero D, López R, Ramón E, Salcedo M. Bacterias relacionadas con vaginosis bacteriana y su asociación a la infección por virus del papiloma humano. Med Clin (Barc) 2018. pii: S0025-7753(18)30087-3.

42. Maganana M, Contreras A, Chavez A, Lizano M, De la Cruz Y, De la Cruz E. Prevalence of sexually transmitted pathogens associated with HPV infection in cervical samples in a Mexican population. J Med Virol 2015 ;87 (12):2098-2105.

43. Di Paola M, Sani C, Clemente A, Lossa A, Perissi E, Castronovo G, Tanturli M, Rivero D, Cozzolino F, Cavalieri D, Carozzi F, De Filippo C, Torcia M. Characterization of cervico-vaginal microbiota in women developing persistent high-risk human papillomavirus infection. Sci Rep 2017;7(1): 10200 .

44. Zhang C, Liu Y, Gao W, Pan Y, Gao Y, Shen J, Xiong H. The direct and indirect association of cervical microbiota with the risk of cervical intraepithelial neoplasia. Cancer Med 2018;7(5):2172-2179.

45. Di Pietro M, Filardo S, Porpora MG, Recine N, Latino MA, Sessa R. HPV/Chlamydia trachomatis co-infection: metaǵenomic analysis of cervical microbiota in asymptomatic women. New Microbiol 2018;41(1):34-41. 